\title{
Governance of Digital Transformation: A Review of the Literature
}

\author{
Jennifer Jewer \\ Memorial University of \\ Newfoundland \\ jenniferj@mun.ca
}

\author{
Nick van der Meulen \\ MIT Sloan Center for Information \\ Systems Research \\ nmeulen@mit.edu
}

\begin{abstract}
Digital transformation (DT) has attracted increased attention across academia and practice, with recent work contributing to an improved understanding of this phenomenon. However, we lack a comprehensive view of how DT should be governed - how do organizational structures, processes, and relational mechanisms around DT decisions influence an organization's ability to achieve its goals? With DT the focus of governance extends beyond just the decision rights and accountabilities of the information technology (IT) unit. Rather than 'just' being an organizational unit, technology is now core to the organization and its operations. This increases the scope to an organizational level of governance; therefore, traditional IT governance mechanisms may not apply as well to DT. This study provides a review of how the DT literature discusses governance, and identifies areas for future research.
\end{abstract}

\section{Introduction}

Digital transformation (DT) has been referred to as "the technology-related phenomenon of our times" [1, p. 2] and has attracted increased attention across academia and practice at a breathtaking pace [2]. The challenges around COVID-19 have amplified the attention on the strategic importance of DT as the pandemic has illustrated the turbulent nature of business ecosystems and the benefits that digital innovation can bring [3]. Recent work has contributed to an increase in understanding of certain aspects of DT, such as strategic responses to digital disruption [4], [5], [6] and assessing the impacts of DT [7]. However, we lack a comprehensive understanding of how DT should be governed - how do organizational structures, processes, and relational mechanisms around DT decisions influence an organization's ability to achieve its goals? In this study, we provide a review of how the DT literature discusses governance. The purpose is to help us to understand how governance of DT enables and/or constrains transformation efforts. We found no extant studies reviewing governance of DT, so the insights are useful to provide a comprehensive overview of how this topic has been studied, and to identify areas for future research.

DT is defined by the changes that digital technologies can bring to a company's business model, its products, organizational structures, and processes [8]. Though the benefits of DT are clear, implementation remains a challenge, with high failure rates [9], [10]. A major driver of the high failure rate is the fact that DT is not just about the technology; it also requires transformation of organizations' structures and contexts that reshape companies and their organizing logics around IT [2].

Governance is a central component of successful DT with effective governance "provid[ing] appropriate levels of coordination and sharing for digital initiatives, in line with the company's structure, culture, and strategic priorities" [11, p. 13]. With DT the focus of governance extends beyond just the decision rights and accountabilities of the IT unit. Rather than 'just' being an organizational unit, technology is now core to the organization, its operations (i.e., everything is about technology and how it drives business), and the products and services it offers to customers. This increases the scope to an organizational level of governance, spanning organizational domains such as business strategy, marketing and sales, production, or human resources.

There is a well-developed area of research around the governance of IT-enabled organizational transformation, and IT governance has been shown to increase the benefits received from these types of IT investments [12]-[14]. However, DT is different from IT-enabled organizational change and it impacts work practices differently [1], [15], [16]. Whereas IT-enabled organizational change is more about transforming work around the core value supporting activities to support the existing value proposition (i.e., technology to increase efficiency of current operations), DT is more about transforming work around the core value defining activities to (re)define new value propositions (i.e., technology to transform the organization) [1] [15]. Vial 
et al. "view DT as an evolution of IT-enabled transformation” [2, p. 133]. DT impacts the scale, scope, and speed at which the organization must change [6]. Therefore, traditional IT governance mechanisms may not apply as well to DT as "they overemphasize the role of hierarchy, propose robust structures that lack agility, and do not account for cross-functional synergies" or very dynamic environments - all of which are prevalent in DT [15, p. 208].

Building on De Haes et al.'s [17] definition of IT governance, we define governance of DT as involving the definition and implementation of processes, structures, and relational mechanisms that enable both business and IT stakeholders to execute their responsibilities in support of DT efforts. These three types of capabilities for governing IT [18] include not only the allocation of formal IT decision-making authority, but also horizontal mechanisms to integrate IT decision-making across business and IT groups. In this study, we examine the DT literature to identify how these three types of governance mechanisms have been applied in the context of DT. The primary goal of this paper, therefore, is to identify the state of the research on governance of DT. The literature review is our analysis and we aim to present the state of this research area and draw insights from our findings to help guide future research.

This paper contributes by providing a review and synthesis of current knowledge on the governance of DT. We advance the understanding of governance in the context of DT and identify how the mechanisms for DT compare to mechanisms as they have been traditionally applied in the context of IT-enabled organizational change. In the next sections we present the methods of our review, and then detail our findings on the governance mechanisms for DT. Finally, we discuss our findings, identify areas for future research, and provide concluding remarks.

\section{Research Design}

We chose to base this review of the literature on governance of DT on Hanelt et al.'s [3] systematic review on DT. This article is the most recent review of the DT literature and the scope is comprehensive. In our review process we approached the governance of DT literature as a subset of the DT body of research. We decided that this was the best approach because it is very difficult to identify an exhaustive list of key search terms for IT governance that would not exclude an article and we wanted to be as inclusive as possible. For example, we were looking for governance structures (i.e., IT expertise at level of board of directors or CIO on executive committee), processes (i.e., IT performance measurement or strategic IS planning) and relational mechanisms (i.e., informal meetings between business and IT leaders or IT leadership) and any new mechanisms that may not have been identified in De Haes and van Grembergen's [19] work. We selected this article as our starting list of mechanisms as this is one of the most cited articles offering a comprehensive list of IT governance mechanisms.

Hanelt et al.'s [3] review included searches for 'digital transformation' and 'digital' AND 'transformation' in EBSCO Business Source Complete database and performed a backward-forward search of the references of included articles, and included publications with at least 20 citations (except for articles published between 2016 and 2018). We examined the 87 articles ${ }^{1}$ listed in [3] looking for any new or existing IT governance mechanisms that were mentioned in these articles.

The analysis of the articles took place in four phases. In the first phase, one of the authors and a research assistant (RA) used the three categories of IT governance mechanisms defined by Peterson [18] to independently code any mechanisms found in the paper. The intention here was to be as inclusive as possible, so as not to omit any mechanisms or papers that might be relevant. We did not want to accidently overlook any relevant articles. The author and the RA then reviewed each other's results and discussed any discrepancies. This process left us with a total of 28 articles - 18 empirical (12 qualitative, three quantitative, and three mixed methods), eight conceptual, and two literature reviews. The second phase involved the two authors independently coding a subset of the IT governance mechanisms found in the papers as specific types of mechanisms (i.e., CIO reporting to CEO, job-rotation or co-location) until agreement was reached. We used De Haes and van Grembergen's [19] list of ITG mechanisms as a guide; if a new mechanism was mentioned then we added a code for this mechanism (i.e., Chief Digital Officer (CDO)). One author then coded the rest of the mechanisms and the other author checked the coding and again discussed any discrepancies. In the third phase the authors worked together to review the coded mechanisms and determine if any could be combined with other mechanisms or if any should be separated into unique mechanisms. Based upon this final list of mechanisms, in the fourth phase the authors first developed key themes that emerged

\footnotetext{
${ }^{1}$ Hanelt et al.'s (2020) review included 279 articles, but due to space constraints, references were provided for only 87 key articles.
} 
from the literature independently and then discussed them to develop the key findings which are discussed in this paper.

\section{Findings}

The governance mechanisms identified in our review are organized according to the type of mechanism - structure, process, or relational mechanism - in Tables 1 to 3. Next to each mechanism we identify an exemplar from the article and the citation of the article. We also list any newly identified mechanisms and whether the articles were conceptual or empirical.

\subsection{Structures}

Structural governance capability concerns the formal devices and mechanisms to enable decisionmaking between business and IT management [18]. Our review found that five of the 12 original structures had been addressed in the context of DT (Table 1). Interestingly, there were no mentions in the articles of the function in the organization responsible for managing IT governance processes, or the various committees other than an IT steering committee.

We found only one article that examined the role of the board of directors in the governance of DT. Based on a review of the literature on the potential impact of disruptive technologies on the role of the board, Evans found a general lack of board preparedness for DT. They argued that "Directors need to gain a better grasp of the disruptive technologies or they will risk their organization not surviving the transition to the new world and markets” [20, p. 218]. Steering committees were only mentioned in three studies. For instance, Chatterjee et al. [21] talked about structural changes such as a task force or an oversight team such as a business advisory council to help determine business priorities for IT investments. Haffke et al. [22] identified the use of steering committees in their field study of 19 large companies.

The integration of governance/alignment tasks through documented roles and/or responsibilities was specifically mentioned in five of the studies. These roles included IT architects facilitating integration [23], IT coordinators facilitating learning across organizational boundaries [24], liaison roles such as a web page managers [21], and unified data organizations to continuously improve products post sale [25]. Sia et al. [5] identified the creation of new roles to help integrate tasks, including new heads of process transformation, customer experience council, and innovation, and the merger of the Technology and Operations departments.
There was only one mention of a mechanism for security. However, rather than a risk officer, Porter and Heppelmann [25] proposed a shared responsibility for security reporting to the CIO, CTO, CDO, or chief compliance officer. They found that security cuts across product development, IT, field service groups and other units, and requires strong collaboration between $R \& D$, IT, and the data organization.

We identified two new structural mechanisms - the $\mathrm{CDO}$, and the innovation lab. First, the importance of leadership of DT efforts was reiterated again and again in the literature; however, it is unclear with whom the decision-making responsibility should lie [4]. In a case study of DBS Bank, Sia et al. [5] identified the importance of acknowledging the role of the CIO on the senior executive team with a convergence of reporting to the CIO. However, others identified the CDO as the “digital torchbearer” responsible to lead DT efforts [22], [26]. Porter and Heppelmann [25] found that digitally transformed manufacturers may have new data organizations which usually are led by a CDO who is responsible for unified data management. Weill and Woerner found that the right executive to lead the transformation depended on "the company's circumstances, the industry environment, and the direction management wants to go" [27, p. 25]. They identified four pathways to DT and recommended either the CIO, CDO, executive of customer experience, and/or CEO/COO to lead the DT depending on the pathway chosen. Furthermore, 14 of the studies specifically mentioned the importance of effective leadership of DT at the C-suite (rather than IT) level (these are identified as relational mechanisms in Table $3)$. Second, the use of an innovation lab/office was discussed in five of the papers. Two of these papers were empirical and found that organizations used this structural element to facilitate knowledge sharing across business and IT units [24] and to incubate and accelerate emerging digital innovations [5]. Similarly, the conceptual papers identified such labs as a way to develop and test new ideas.

We also found that four papers specifically identified the need to change the governance structure as the organization experienced different degrees of DT. Porter and Heppelmann [25] discussed how virtually every traditional function will need to be restructured given the dramatic realignment of tasks and roles and how the coexistence of the new and the old will complicate organizational structures. Matt et al. [4] argued that the extent of structural changes depends on the type and extent of the digital changes. If the changes are concentrated, then the approach might be to integrate the new operations into existing corporate structures, while for more substantial changes it might be better to create a separate subsidiary within the firm. This need 
for a separate unit to guide DT was echoed by Haffke et al. [22]. In a study of 19 large companies, they describe how companies separated their IT function into two models - the traditional role as a service provider and focused on performance, and the agile role to explore and experiment with new technologies that can be leveraged for DT. They argued that this bimodal IT function allows the IT function to operate in two parallel modes and found four archetypes of bimodal IT with different levels of structural separation between the traditional and the agile depending on the organizations' needs and stage in the DT process. Schwer and Hitz [28] proposed a new agile form for management of DT called holacracy to replace the traditional management hierarchy. The authors question whether hierarchy is still needed in companies and proposed a new structure with no managerial positions, conventional structure, and job titles. The authors acknowledge the difficulty for big firms to abolish hierarchy and discuss how organizations can move to a dual operating system over time with hierarchical and networked forms of organizing. This practice of evolving structure reflects companies undergoing fundamental changes to organizational functions, roles, and responsibilities over time, without knowing upfront which (combination) of these elements will be required.

Table 1. Governance structures for digital transformation

\begin{tabular}{|c|c|}
\hline Structures & Description and source \\
\hline $\begin{array}{l}\text { IT expertise at level of board of } \\
\text { directors }\end{array}$ & *Need to recruit and educate the board [20] \\
\hline CIO on executive committee & CIO on senior executive team [5] \\
\hline $\begin{array}{l}\text { CIO reporting to CEO and/or COO } \\
\text { (Chief Operational Officer) }\end{array}$ & CIO reporting to CEO and convergence of reporting to CIO [5] \\
\hline $\begin{array}{l}\text { IT steering committee (IT investment } \\
\text { evaluation / prioritization at executive / } \\
\text { senior management level) }\end{array}$ & $\begin{array}{l}\text { Steering committees specific to each mode of bimodal design [22]; } \\
\text { taskforce or oversight teams [21]; *steering committee with thought } \\
\text { leaders across various business units, who champion opportunities, share } \\
\text { expertise and facilitate collaboration [25] }\end{array}$ \\
\hline Security / compliance/ risk officer & *Shared responsibility for security [25] \\
\hline $\begin{array}{l}\text { Integration of governance/ alignment } \\
\text { tasks in roles and responsibilities }\end{array}$ & $\begin{array}{l}\text { IT architect deployed to facilitate integration [23]; IT coordinator [24]; } \\
\text { new heads of process transformation, innovation, customer experience, } \\
\text { etc. [5]; liaison roles (e.g., web page manager) [21]; *new forms of } \\
\text { cross-functional collaboration through a unified data organizations or } \\
\text { groups charged with optimizing customer relationships [25] }\end{array}$ \\
\hline \multicolumn{2}{|l|}{ Added Mechanisms } \\
\hline Chief Digital Officer & $\begin{array}{l}\text { CDO lead divisional agile form (bimodal) and CIO lead the other efforts } \\
\text { [22]; CDO digital torchbearer [26]; The right choice will depend on the } \\
\text { situation - CEO, COO, CDO, CIO, executive [27]; *no clear answer } \\
\text { which senior manager should be in charge of DT strategy (CDO, CI0, } \\
\text { CEO)[4]; *CDO helps shape and drive the vision for DT [29]; *new data } \\
\text { organizations usually are led by a CDO who is responsible for unified } \\
\text { data management [25] }\end{array}$ \\
\hline Innovation lab/office & $\begin{array}{l}\text { Innovation board to facilitate knowledge sharing [24]; innovation } \\
\text { council/office to incubate and accelerate innovations [5]; innovation hub } \\
\text { for new ways of knowledge sharing [30]; *open innovation gateway to } \\
\text { develop and test ideas [29]; *innovation lab, IBM Innovation Jam, } \\
\text { Deloitte Greenhouses [31]; *innovation lab for testing technologies [32] }\end{array}$ \\
\hline \multicolumn{2}{|c|}{$\begin{array}{l}\text { Structures not discussed in the DT literature: } \\
\text { IT strategy committee at level of board of directors; IT audit committee at level of board of directors; IT governance } \\
\text { function; IT project steering committee; IT security steering committee; Architecture steering committee }\end{array}$} \\
\hline * conceptual paper (otherwise the paper & empirical) \\
\hline
\end{tabular}

\subsection{Processes}

The process governance capability concerns the "formalization and institutionalization of strategic IT decision-making or IT monitoring procedures” [18, p.
15]. Most of the established IT governance process mechanisms identified by De Haes and van Grembergen [19] were not found in our review (Table 2). One conceptual study discussed IT performance measurement [4]. They talked about the importance of 
constant reassessment of DT strategies to ensure progress is being made and to benchmark thresholds for corrective actions.

The processes that were discussed the most in the DT literature were those to integrate business and IT. We identified this as a new process capability. Hansen et al. [24] present the Participatory Process Model (PPM), a four-step process to guide facilitation between IS and business leaders. They also discussed the use of campaigns to market success stories, and the use of an incremental process to explore and test digital innovations. Porter and Heppelmann [25] discussed how far more intense coordination among functions is now required, and that there need to be formal processes for product development, supply chain management, order processing, etc. in which multiple units have roles and IT and R\&D must integrate their activities on a continual basis. In their case study, Sia et al. [5] reported that the organization found technology road-mapping workshops useful in the DT process. Bharadwaj et al. [6] emphasized the need for business and IT integration commenting that with DT there is a new mandate for IT and for the CIO, stating that digital business strategy is more than cross-functional, it is trans-functional. They argued that "the time is right to rethink the role of IT strategy, from that of a functional-level strategy aligned but essentially always subordinate to business strategy - to one that reflects a fusion between IT strategy and business strategy" [p. 472]. Relatedly, there was not a focus on the process capability of strategic IS planning, the focus was more about digital transformation strategy, which according to Matt et al. "serves as a central concept to integrate the entire coordination, prioritization, and implementation of digital transformations within a firm” [4, p. 339].

We also identified agile methods as a new mechanism. We found that these procedures that focus on agility, rather than traditional waterfall approaches that can be more constrained were used by some organizations in their DT efforts. For instance, Ashwell found that intelligence organizations develop an agile process to develop rapidly required capabilities and to adopt new technologies practices, "start small, scale fast and fail cheap" [29, p. 408]. Haffke found that the agile mode of the IT function were formed to foster "creative working, faster decision making and improved collaboration" [22, p. 104]. The agile mode follows a "light touch governance model" and allows projects to skip certain process steps to gain speed and agility.

Table 2. Governance processes for digital transformation

\begin{tabular}{|l|l|}
\hline Processes & Description and source \\
\hline IT performance measurement & * benchmark thresholds and constant reassessment of DT strategies [4] \\
\hline Added Mechanisms & $\begin{array}{l}\text { Participatory Process Model (PPM), campaign to market success stories, } \\
\text { incremental processes to explore and test [24]; monitor the maturity of } \\
\text { bimodal and change if necessary [22]; technology road mapping } \\
\text { workshops [5]; *digital business strategy is more than cross-functional - } \\
\text { it is trans-functional [6]; *formal processes for product development, } \\
\text { supply chain management, etc. in which multiple units have roles, IT } \\
\text { and R\&D must integrate their activities on a continual basis [25] }\end{array}$ \\
\hline $\begin{array}{l}\text { Processes to integrate business and IT } \\
\text { Agile methods }\end{array}$ & $\begin{array}{l}\text { Lean thinking, agile and scalable digital operations [5]; *design } \\
\text { thinking, scrum, introduce new forms of work and methods [31]; agile } \\
\text { approach to capability development [29]; platform-based governance } \\
\text { enables an agile and experimentation-based solutions development } \\
\text { approach [33]; agile mode of the IT function to focus on speed and } \\
\text { experimentation [22]; use agile and minimum viable product concepts } \\
\text { and constant enhancements to build and test new services [23] }\end{array}$ \\
\hline $\begin{array}{l}\text { Processes not discussed in the DT literature: } \\
\text { Strategic information systems planning; Portfolio management (incl. business cases, information economics, } \\
\text { Seturn on Investment, payback); Charge back arrangements total cost of ownership (e.g., Activity based costing); } \\
\text { gervice level agreements; IT governance framework COBIT; IT governance assurance and self-assessment; Project } \\
\text { COSO / ERM /management methodologies; IT budget control and reporting; Benefits management and reporting; }\end{array}$ \\
\hline * conceptual paper (otherwise the paper is empirical) \\
\hline
\end{tabular}

\subsection{Relational Mechanisms}

The relational mechanisms capability refers to "the active participation of, and collaborative relationships among corporate executives, IT management and business management" [18, p. 15]. We found specific evidence for three out of 10 of these mechanisms, and 
identified three new mechanisms to facilitate collaboration (Table 3). We did not find evidence of jobrotation, cross-training, business/IT account management by means of account managers who act as in-between, informal meetings between business and IT executives, or of internal corporate communication regularly addressing general IT issues. We also did not find evidence of the systematic sharing of knowledge on IT governance or of IT governance awareness campaigns.
Co-location of business and IT people was recommended by Berman and Marshall as part of a Digital Reinvention Framework for organizations to help orchestrate connectivity and interactivity [26]. Based on their large-scale survey of businesses and government executive they found that "functional or business unit groups may become insular and selffocused, losing sight of overall strategic goals” [26, p. $16]$.

Table 3. Governance relational mechanisms for digital transformation

\begin{tabular}{|c|c|}
\hline Relational Mechanisms & \\
\hline Co-location & $\begin{array}{l}\text { IT and the business to work together (co-location, cross functional tours } \\
\text { of duty, combined planning exercises) [26] }\end{array}$ \\
\hline $\begin{array}{l}\text { Executive / senior management giving } \\
\text { the good example }\end{array}$ & $\begin{array}{l}\text { Senior business leaders work with IT leaders [22]; CIO or CDO to drive } \\
\text { the appointment of a C-suite leader, active CIO should partner with this } \\
\text { individual to be actively involved in workplace redesign [30]; involve } \\
\text { IS leader in business unit meetings when discussing strategic issues [24] }\end{array}$ \\
\hline IT leadership & $\begin{array}{l}\text { Senior business leaders work with IT leaders [22]; IT leader has freedom } \\
\text { to make IT decisions [24]; CIO on senior executive team [5] }\end{array}$ \\
\hline \multicolumn{2}{|l|}{ Added Mechanism } \\
\hline Leadership & $\begin{array}{l}\text { Effective leadership required to ensure org learning and commitment of } \\
\text { resources [34]; top management championship [21]; transformational } \\
\text { leadership to first change the characteristics of culture and then facilitate } \\
\text { e-business adoption [35]; visionary CEO [5]; leadership and drive from } \\
\text { all C-suite [36]; senior business leaders work with IT leaders [22]; } \\
\text { leadership - roll up sleeves; bring together larger groups [37]; strong } \\
\text { leaders with vision [38]; increase capacity for change [39]; signals } \\
\text { importance of innovation, clear obstacles, improve ideas [40]; lead the } \\
\text { change [41]; dynamic managerial capabilities [42]; *Leadership is } \\
\text { important to DT [32]; *new top management (eLeadership) and new } \\
\text { middle management (eChampions) to develop strategic vision and } \\
\text { execute changes in e-government [43] }\end{array}$ \\
\hline Cross-functional teams & $\begin{array}{l}\text { Cross-functional digital workplace leadership teams (HR, Facilities, } \\
\text { Legal, communications) [30]; *US Defence Intelligence Agencies } \\
\text { (DIA) Innovation Strategy identify need to develop mission-focused } \\
\text { cross-functional teams [29]; new organizational unit "digital factory" - } \\
\text { business and IT worked together (cross-functional teams to design, build } \\
\text { \& deploy new digital solutions [33]; *embedding IT teams within R\&D } \\
\text { departments, cross-functional product design teams [25] }\end{array}$ \\
\hline $\begin{array}{l}\text { Technology to facilitate knowledge } \\
\text { sharing - the need for collaborative } \\
\text { systems }\end{array}$ & $\begin{array}{l}\text { Identified systems for knowledge/data sharing as one of the levers to } \\
\text { enable employee connectedness [30]; unified communication platform, } \\
\text { enterprise portal, collaborative platform and internal crowdsourcing [5]; } \\
\text { *importance of integrating inter and intra-org processes through } \\
\text { capabilities enabled by collaborative systems, KMS, e-business systems } \\
\text { to coordinate the activities of a distributed network of firms [44]; } \\
\text { platform governance - embedding governance rules and standards into } \\
\text { the digital services platform, ensuring desirable access and use of IT } \\
\text { through automated processes [33] }\end{array}$ \\
\hline \multicolumn{2}{|c|}{$\begin{array}{l}\text { Relational mechanisms not discussed in the DT literature } \\
\text { Job-rotation; Cross-training; Knowledge management (on IT governance); Business/IT account management; } \\
\text { Informal meetings between business and IT executive/ senior management; Corporate internal communication } \\
\text { addressing IT on a regular basis; IT governance awareness campaigns }\end{array}$} \\
\hline \multicolumn{2}{|c|}{ * conceptual paper (otherwise the paper is empirical) } \\
\hline
\end{tabular}


There was evidence of executives and senior management leading by example by acting together. Haffke et al. [22] documented the importance of senior business leaders working with IT leaders in DT, and in their two case studies Hansen et al. [24] found that it was important to involve IS leaders in business unit meetings when discussing strategic issues. Dery et al. [30] found that the CIO or CDO needs to drive the appointment of a C-suite leader with end-to-end accountability and actively partner with this individual to be involved in workplace redesign.

There were a limited number of papers that specifically identified IT leadership as a relational mechanism. However, the importance of the role of the CIO, and CDO was found in the literature, and organizational leadership was documented thoroughly. We only found three papers that specifically talked about IT leadership's importance in articulating IT's role in the company; however, this could be inferred from most papers with some disagreement on whether this should be the role of the IT leadership, executive leadership, or jointly carried out. We found 14 articles that specifically discussed the role of leadership in DT and we have identified this as a new relational mechanism. For instance, they talked about the importance of transformational leadership to first change the culture [35], the importance of leadership to increase capacity for change [39], and to signal the importance of innovation [40].

We also identified cross-functional teams as a new relational mechanism. For instance, Ashwell [29] talked about how the US Defence Intelligence Agency's Innovation strategic plan describes the need to develop mission-focused cross-functional teams. Dery et al. found that a key part of the DT journey at one of the organizations they studied was a crossfunctional leadership team (legal, marketing, strategy and HR) to help simplify business rules and remove speedbumps. Another of the organizations they studied restructured their business from "corporate hierarchies to cross-functional competence networks and agile teams" [30, p. 143]. In their case study Gregory et al. [33] found that as part of their DT a global bank established a new organizational unit called a "digital factory" where business and IT worked together as cross-functional teams to design, build and deploy new digital solutions for consumers.

Finally, we identified technology to facilitate knowledge sharing as a new relational mechanism. Dery et al. [30] identified systems for knowledge/data sharing as one of the levers to enable employee connectedness. For example, the companies implemented new technologies to support and enable work activities for innovation. Sia et al. [5] found that investments in collaborative technology, such as unified communication infrastructure, telepresence videoconferencing systems and enterprise portals, facilitated enterprise coordination. For example, an eforum was set up on the internal enterprise portal to encourage staff to provide feedback or make improvement suggestions directly to the CEO. They also found that such collaborative technologies also enabled crowdsourcing of innovate ideas from employees. Yoo et al. [44] talked about the importance of integrating not only intra-, but also interorganization processes through capabilities enabled by collaborative systems, knowledge management systems, and e-business systems to coordinate the activities of a distributed network of firms. In doing so they acknowledged the need to coordinate across organizational boundaries, what they referred to as a doubly distributed network. Gregory et al. [33] found that the bank they studied embedded governance rules and standards into the digital services platform and ensured desirable access and use of IT through automated processes. They referred to this as platform governance.

\section{Discussion of Findings and Future Research}

Our review of the literature suggests that DT transforms IT governance and that this area is apt for future research. 28 of the 87 DT articles mentioned some aspects of governance; however, only one article focusing specifically on governance [33] and only five others discussed four or more governance mechanisms [22], [24], [25], [29], [30].

DT challenges the foundations of IT governance, rather than based on the alignment of IT and business, governance of DT is focused on developing and implementing the digital strategy of the whole organization. DT promotes digital development and use throughout the organization, thus governance is focused not just on the IT unit, but on the whole organization. This puts into question the specific role of the IT unit in governing technology in an organization. This is evident in the mechanisms that we found, and in those that we did not find in our review. Many of the traditional mechanisms [19] (e.g., different IT steering committees, IT governance frameworks or job-rotation) were not found in our review. Interestingly, there was no empirical examination of the role of the board of directors in such a transformation. However, studies completed since this review period have found that a digital savvy board is a financial performance differentiator [45], 
[46]. Thus future research could examine what role these mechanisms play in DT.

We found that the mechanisms that dominated were those that emphasized the importance of collaboration between IT and the business, with much research noting the need to change their traditional roles and the need for a cultural shift. For example, to view the IT unit's role as an integral part of value creation, not just a provider of technology. This is exemplified in how the role of leadership is represented in the DT literature. Leadership was identified as playing a key role in DT; however, in many studies, this role was not identified as primarily the responsibility of the CIO. There was no consensus on who should be leading DT, but a majority of the studies specifically mentioned the importance of the role that all leaders in the organization play in DT.

Further supporting the expanded scope of IT governance to the whole organization, we found that DT is associated with key structural changes, and various organizational models were identified. The changes we found in the literature were primarily focused on how to enable cross-functional collaboration and how to connect organizational and IS strategy. We found that organizations do this not only through structures, but also through processes and relational mechanisms which work together to create an environment conducive to DT. Structures include roles to integrate governance and alignment tasks, the creation of innovation labs or hubs to facilitate knowledge sharing, the creation of a new position such as a CDO, or the expansion of responsibilities of existing positions (i.e., CIO, COO, or CEO) to include such integration. Processes including procedures to integrate business and IT, such as the PPM [24], technology road-mapping workshops [5], or a focus on digital transformation strategy rather than IS strategy [4], and agile methods focused on speed and experimentation were found to enable DT. Relational mechanisms emphasized the need for senior business leaders to work with IT leaders, and the formation of cross-functional teams to facilitate DT. Many of these mechanisms are not new, but the DT literature highlights the increased need for them to enable the collaboration between business and IT that is necessary for DT. We propose that the IT unit has a role to play in governing technology use, but from a perspective of supporting and championing solutions and practices, rather than as a 'gatekeeper' and sole purveyor of technology in the organization. Further research of this and other mechanisms could help advance theory and also provide much needed guidance for firms on how to formulate, implement and evaluate DT [4].
Another aspect that requires future research in particular is the use of technology as a governance mechanisms - governance via IT as opposed to governance of IT [47]. The literature indicated that some organizations undergoing the DT process had used technology to govern DT. Technology, such as collaborative platforms, seemed to be predominately used as relational mechanisms to enable information sharing. However, Gregory et al. [33] identified platform-based governance as a mechanism that may extend beyond a means to collaborate, but also to embed governance rules and standards into the digital services platform. One benefit of platform governance is that the embedded mechanisms may be more easily adaptable. Research in this area would help to advance our understanding of how technologies such as digital platforms and infrastructures are impacting governance of DT.

Our results also highlight that an organization's governance needs change as it transforms digitally the mechanisms, digital strategy and architecture are intertwined and in a state of continuous evolution. Firms need to find new procedures for formulating, implementing, evaluating, and adopting DT strategies [4]. Outdated policies and procedures, complex processes, and outdated systems can be speedbumps to DT [30]. Managers need to negotiate an "innovation balance" [7] between control and flexibility to govern DT. We found that organizations have used new organizational structures, such as bimodal [22] or holacracy [31] approaches to governance which are designed to change over time to foster agility and innovation. Processes can also change, for example, using the PPM as needed to encourage a collaborative approach from business and IT [24], or implementing technology to replace or support relational mechanisms as the organization develops a digital infrastructure. Gregory et al. [33] found that IT governance changed as organizations were impacted by the DT of IT consumerization. They found that "IT governance misalignment" or "bypassing” (i.e., when the governance does not support how the actors want or need to work) resulted in a move to more platformbased governance. The challenges with how these new organizational forms can coexist with traditional structures also need to be addressed [25]. Therefore, an area for future research is to examine how this shift in governance of DT unfolds over time.

Our review is limited by the constraint of basing our search on the articles published in Hanelt's [3] systematic review. A more extensive review would have included the entire 279 articles found by Hanelt and updated the search to include articles published since 2018. However, this preliminary review has indicated that this is an area that has many 
opportunities for future researchers to contribute to theory and practice as there is a need to re-assess the underlying assumptions of governance of DT. Our review is also limited by focusing on how to govern, rather than on what or who to govern [48]. Future research could categorize the findings according to all three dimensions.

In addition to the implications for research, this study provides insights to IT and business managers as DT has blurred the boundaries between IT and the business. Our review has highlighted the important role of leadership as organizations transform digitally, and how traditional and new mechanisms have been used to govern DT. A greater understanding of these mechanisms will enable managers to pro-actively adapt these mechanisms to support and guide their organizations' transformation.

\section{Conclusion}

There is an increasing amount of research on DT, and much of it points to the need for organizational change. At the same time, however, there is little understanding of how DT and the associated organizational changes should be governed. Therefore, in this study, we examine how traditional governance mechanisms have been used to guide organizations through these transformations and we identify new mechanisms. We found that governance must adapt as organizations digitally transform so that governance serves as an enabling constraint for DT. Overall, we hope that this review contributes to help future researchers explore the nature of governance of DT to help organizations take advantage of the opportunities that digital technologies allow.

\section{References}

[1] L. Wessel, A. Baiyere, R. Ologeanu-Taddei, J. Cha, and T. B. Jensen, "Unpacking the difference between digital transformation and it-enabled organizational transformation,” J. Assoc. Inf. Syst., vol. 22, no. 1, pp. 102-129, 2021, doi: 10.17705/1jais.00655.

[2] G. Vial, "Understanding digital transformation: A review and a research agenda," J. Strateg. Inf. Syst., vol. 28, no. 2, pp. 118-144, 2019, doi: 10.1016/j.jsis.2019.01.003.

[3] A. Hanelt, R. Bohnsack, D. Marz, and C. Antunes Marante, "A Systematic Review of the Literature on Digital Transformation: Insights and Implications for Strategy and Organizational Change,” J. Manag. Stud., vol. 22, no. 1, pp. 102129, 2020, doi: 10.1111/joms.12639.

[4] C. Matt, T. Hess, and A. Benlian, "Digital Transformation Strategies,” Bus. Inf. Syst. Eng., vol. 57, no. 5, pp. 339-343, 2015.

[5] S. K. Sia, C. Soh, and P. Weill, "How DBS bank pursued a digital business strategy,” MIS Q. Exec., vol. 15, no. 2, pp. 105-121, 2016.

[6] A. Bharadwaj, O. A. El Sawy, P. A. Pavlou, and N. Venkatraman, "Digital Business Strategy: Toward a Next Generation of Insights," MIS Q., vol. 37, no. 2, pp. 471-482, 2013.

[7] F. Svahn, L. Mathiassen, and R. Lindgren, "Embracing digital innovation in incumbent firms: How Volvo Cars managed competing concerns," MIS Q. Manag. Inf. Syst., vol. 41, no. 1, pp. 239253, 2017, doi: 10.25300/MISQ/2017/41.1.12.

[8] T. Hess, A. Benlian, C. Matt, and F. Wiesböck, "Options for formulating a digital transformation strategy,” MIS Q. Exec., vol. 15, no. 2, pp. 123139, 2016, doi: 10.4324/9780429286797-7.

[9] G. C. Kane, "Digital Transformation Is a Misnomer,” MIT Sloan Manag. Rev., 2018, [Online]. Available:

https://sloanreview.mit.edu/article/digitaltransformation-is-a-misnomer/.

[10] P. Lewis, "Where businesses go wrong with digital transformation,” Forbes, 2019, [Online]. https://www.forbes.com/sites/phillewis1/2019/07/ 31/where-businesses-go-wrong-with-digitaltransformation/\#6fedb6dd70bb.

[11] M. Tannou and G. Westerman, "Governance: A Central Component of Successful Digital Transformation,” MITCDB CapGemini Consult., pp. 14-21, 2012.

[12] J. Jewer and K. N. McKay, “Antecedents and consequences of board IT governance: Institutional and strategic choice perspectives,” $J$. Assoc. Inf. Syst., vol. 13, no. 7, 2012.

[13] S. De Haes and W. Van Grembergen, "Improving enterprise governance of IT in a major airline: A teaching case,” J. Inf. Technol. Teach. Cases, vol. 3, no. 2, pp. 60-69, 2018.

[14] P.-J. Wu, D. W. Straub, and T.-P. Liang, "Mechanisms and strategic alignment influence organizational performance,” MIS Q., vol. 39, no. 2, pp. 497-518, 2015.

[15] J. W. Ross, C. M. Beath, and I. M. Sebastian, “Digitized $\neq$ Digital,” MIT CISR Res. Brief., vol. XVII, no. 10, pp. 1-4, 2017.

[16] G. DeLone, W., Migliorati, D. Vaia, "Digital IT governance," in CIOs and the Digital Transformation, Springer, pp. 205-230, 2018.

[17] S. De Haes, W. Van Grembergen, J. Anant, and T. Huygh, Enterprise Governance of Information Technology. Achieving Alignment and Value in Digital Organizations, Springer, 2020.

[18] R. Peterson, "Crafting Information Technology Governance,” Inf. Syst. Manag., vol. 21, no. 4, pp. 7-22, 2004, doi: 10.1201/1079/44819.32.6.20041201/85112.1.

[19] S. de Haes and W. van Grembergen, “An Exploratory Study into IT Governance Implementations and its Impact on Business/IT Alignment,” Inf. Syst. Manag., vol. 26, no. 2, pp. 
123-137, 2009, doi: $10.1080 / 10580530902794786$

[20] G. L. Evans, "Disruptive technology and the board: the tip of the iceberg," Econ. Bus. Rev., vol. 3, no. 17, pp. 205-223, 2017.

[21] D. Chatterjee, R. Grewal, and V. Sambamurthy, "Shaping up for E-commerce: Institutional enablers of the organizational assimilation of Web technologies,” MIS Q. Manag. Inf. Syst., vol. 26, no. 2, pp. 65-90, 2002, doi: 10.2307/4132321.

[22] I. Haffke, B. Kalgovas, A. Benlian, "Options for transforming the IT function using bimodal IT," MIS Q. Exec., vol. 16, no. 2, pp. 101-120, 2017.

[23] I. M. Sebastian, K. G. Moloney, J. W. Ross, N. O. Fonstad, C. Beath, and M. Mocker, "How big old companies navigate digital transformation," MIS Q. Exec., vol. 16, no. 3, pp. 197-213, 2017, doi: 10.4324/9780429286797-6.

[24] A. M. Hansen, P. Kraemmergaard, and L. Mathiassen, "Rapid adaptation in digital transformation: A participatory process for engaging is and business leaders," MIS Q. Exec., vol. 10, no. 4, pp. 175-185, 2011.

[25] M. E. Porter and J. E. Heppelmann, "How Smart, Connected Products are Transforming Companies,” Harv. Bus. Rev., vol. October, pp. 97-114, 2015.

[26] S. Berman and A. Marshall, "The next digital transformation: From an individual-centered to an everyone-to-everyone economy," Strateg. Leadersh., vol. 42, no. 5, pp. 9-17, 2014, doi: 10.1108/SL-07-2014-0048.

[27] P. Weil and S. L. Woerner, "Is Your Company Ready,” Mit Sloan Manag. Rev., pp. 21-26, 2018.

[28] K. Schwer and C. Hitz, "Designing organizational structure in the age of digitization," J. East. Eur. Cent. Asian Res., vol. 5, no. 1, pp. 1-12, 2018, doi: 10.15549/jeecar.v5i1.213.

[29] M. L. Ashwell, "The digital transformation of intelligence analysis,” J. Financ. Crime, vol. 24, no. 3, pp. 393-411, 2017.

[30] K. Dery, I. M. Sebastian, N. van der Meulen, "The digital workplace is key to digital innovation," MIS Q. Exec., vol. 16, no. 2, pp. 135-152, 2017.

[31] K. Vey, T. Fandel-Meyer, J. S. Zipp, and C. Schneider, "Learning \& Development in Times of Digital Transformation: Facilitating a Culture of Change and Innovation,” Int. J. Adv. Corp. Learn., vol. 10, no. 1, p. 22, 2017.

[32] T. Canaday, "Evolving a payments business to meet the demands of a distributed economy," $J$. Payments Strateg. Syst., vol. 11, no. 1, pp. 15-22, 2017.

[33] R. W. Gregory, E. Kaganer, O. Henfridsson, and T. J. Ruch, "It consumerization and the transformation of it governance," MIS Q. Manag. Inf. Syst., vol. 42, no. 4, pp. 1225-1253, 2018, doi: 10.25300/MISQ/2018/13703.

[34] S. F. Wamba and A. T. Chatfield, “A contingency model for creating value from RFID supply chain network projects in logistics and manufacturing environments,” Eur. J. Inf. Syst., vol. 18, no. 6, pp. 615-636, 2009, doi: 10.1057/ejis.2009.44.

[35] L. Alos-Simo, A. J. Verdu-Jover, and J. M. Gomez-Gras, "How transformational leadership facilitates e-business adoption,” Ind. Manag. Data Syst., vol. 117, no. 2, pp. 382-397, 2017.

[36] A. B. Gerth and J. Peppard, "The dynamics of CIO derailment: How CIOs come undone and how to avoid it,” Bus. Horiz., vol. 59, no. 1, pp. 61-70, 2016, doi: 10.1016/j.bushor.2015.09.001.

[37] M. Gale and C. Aarons, "Why people matter far more than digital technology or capital,” Strateg. HR Rev., vol. 17, no. 1, pp. 29-32, 2018, doi: 10.1108/shr-11-2017-0082.

[38] G. Westerman, D. Bonnet, and A. McAfee, "The Nine Elements of Digital Transformation,” MIT Sloan Manag. Rev., vol. 55, pp. 1-6, 2014.

[39] H. C. Lucas and J. M. Goh, "Disruptive technology: How Kodak missed the digital photography revolution,” J. Strateg. Inf. Syst., vol. 18, no. 1, pp. 46-55, 2009, doi: 10.1016/j.jsis.2009.01.002.

[40] J. Karimi and Z. Walter, "The role of dynamic capabilities in responding to digital disruption: A factor-based study of the newspaper industry," $J$. Manag. Inf. Syst., vol. 32, no. 1, pp. 39-81, 2015, doi: 10.1080/07421222.2015.1029380.

[41] B. J. C. Steinhoff, A. C. Lewis, and G. Cipp, "The March of the Robots," The J. of Government Financial Management, pp. 26-34, 2018.

[42] L. Li, F. Su, W. Zhang, and J. Y. Mao, "Digital transformation by SME entrepreneurs: A capability perspective,” Inf. Syst. J., vol. 28, no. 6, pp. 1129-1157, 2018, doi: 10.1111/isj.12153.

[43] J. Nograšek, "Change Management as a Critical Success Factor in e-Government Implementation," Bsrj, vol. 2, no. 2, pp. 13-24, 2011, doi: 10.2478/v10305-012-0016-y.

[44] Y. Yoo, O. Henfridsson, and K. Lyytinen, "The new organizing logic of digital innovation: An agenda for information systems research," Inf. Syst. Res., vol. 21, no. 4, pp. 724-735, 2010, doi: 10.1287/isre.1100.0322.

[45] P. Weill, G. Scholten, and S. L. Woerner, "Working with boards on digital," MIT CISR Res. Brief., vol. XIX-9, no. Sep 19, 2019, [Online]. https://cisr.mit.edu/publication/2019_0901_Princip alDigitalBoard_WeillScholtenWoerner.

[46] P. Weill, T. Apel, S. L. Woerner, and J. S. Banner, "It pays to have a digitally savvy board," MIT Sloan Manag. Rev., vol. Spring, 2019, [Online]. Available: https://sloanreview.mit.edu/article/itpays-to-have-a-digitally-savvy-board/.

[47] P. L. Drnevish and D. C. Croson, "Information technology and business-level strategy: toward an integrated theoretical perspective,” MIS Q., vol. 37, no. 2, pp. 483-509, 2013.

[48] A. Tiwana, B. Konsynski, and N. Venkatraman, "Information Technology and Organizational Governance: The IT Governance Cube,” $J$. Manag. Inf. Syst., vol. 30, no. 3, pp. 7-12, 2013. 